\title{
Risk of recurrence of cerebral venous and sinus thrombosis during subsequent pregnancy and puerperium
}

\author{
S Mehraein, H Ortwein, M Busch, M Weih, K Einhäupl, F Masuhr
}

J Neurol Neurosurg Psychiatry 2003;74:814-816

\begin{abstract}
Objective: To assess the risk of recurrence of cerebral venous and sinus thrombosis (CVST) during subsequent pregnancy and puerperium in women with previous cerebral venous occlusive disease.

Methods: The authors retrospectively studied the relapse rate of CVST and the incidence of extracerebral venous thrombosis during subsequent pregnancies in 39 women (from 125 patients with CVST) who suffered a CVST at childbearing age.

Results: Mean follow up was 10.25 years (range 1 to 20). Twenty two pregnancies and 19 births were observed in 14 women without evidence of either recurrence of CVST or extracerebral venous thrombosis. One pregnancy occurred during oral anticoagulation and was interrupted and two pregnancies ended with spontaneous abortions. Low dose heparin had been given during five pregnancies.

Conclusions: The risk of recurrence for CVST during pregnancy seems to be low and these data do not justify a negative advice on pregnancy in women with previous CVST. Further studies are needed to evaluate the need for a prophylactic anticoagulation during pregnancy and puerperium.
\end{abstract}

$\mathrm{H}$ ormonal changes during pregnancy and the puerperium carry an increased risk of venous thromboembolism (VTE) including cerebral venous and sinus thrombosis (CVST). ${ }^{1-3}$ Very little is known about the relapse rate during pregnancy and puerperium in women with a history of CVST. As CVST is nowadays largely a disease of younger women and hormonal factors such as the intake of oral contraceptives $^{45}$ or pregnancy are important risk factors in a large proportion of female patients, counselling of such women regarding future pregnancies remains a problem in clinical practice. We studied the course and complications of further pregnancies as well as the relapse rate in women with previous CVST at childbearing age.

\section{PATIENTS AND METHODS}

A total of 125 consecutive patients with CVST treated between 1976 and 1996 were identified from hospital charts. Diagnosis had been confirmed by conventional angiography or magnetic resonance angiography in all patients. Eighteen patients (14.6\%) had died during the acute stage and 12 had died during the follow up period. Additional 10 patients were lost to follow up and three refused to participate in the study. The remaining 82 patients were eligible for the study. Of these, 39 $(47.5 \%)$ were women and had been at childbearing age (18-40 years) when the CVST occurred.

Data were obtained by phone interviews using a standardised questionnaire. It contained questions on the CVST relapse rate and the long term outcome and was sent to all 82 patients. One part of the questionnaire focused on subsequent pregnancies asking for ( 1 ) recurrence of CVST (and its delay to the previous CVST and how the diagnosis was established) (2) incidence of other venous thrombotic events (3) incidence of other pregnancy related complications, and (4) the use and duration of anticoagulation with heparin. Patients who declined a telephone interview were sent the questionnaire by mail. If questions were not or equivocally answered in the mailed questionnaires, the patients or the treating physicians were contacted by phone for clarification or completion of data. The presented analysis is focused on the risk of CVST recurrence in women with subsequent pregnancies. In addition, the recurrence rate of all 82 patients is presented.

\section{RESULTS}

Mean follow up was 10.25 years (range 1 to 20). Recurrence of CVST as confirmed by conventional angiography or magnetic resonance angiography was observed in five patients $(6 \%)$ of the entire study population. Four patients had a relapse within the first 19 months after their initial CVST and one patient after 50 months. Thus, $80 \%$ of all relapses occurred within the first two years with a mean latency of 10.3 months. No patient with recurrent CVST was left with disabling neurological deficits.

In the subgroup of 39 women at childbearing age, 22 pregnancies occurred in 14 patients (two in four women and three in two women) during the follow up period. The mean age of these 14 women at the time of CVST had been 25.6 years (range 19-39) and the mean interval between CVST and the subsequent pregnancy was 5.3 years (range $1-18$ ).

No recurrence of CVST and no extracerebral thrombotic complications occurred during the pregnancies and postpartum periods including four women who initially presented with pregnancy related CVST. Nineteen healthy children were born. One pregnancy occurred during oral anticoagulation and was interrupted in the 10th week because of the teratogenic risk of coumarins, one pregnancy ended with spontaneous abortion in the 10th week, and one fatal stillbirth occurred in the 16th week of gestation. One women suffered from two unexplained grand mal seizures during pregnancy without evidence of recurrent CVST, and two women developed gestosis.

Low dose heparin was given subcutaneously during five pregnancies: in two cases during the entire pregnancy and puerperium, in one case from the 16th week of gestation and in two cases from the 36th gestation week until two to eight weeks after delivery. No anticoagulation was given during the remaining 14 pregnancies and puerperium periods.

Abbreviations: CVST, cerebral venous and sinus thrombosis; VTE, venous thromboembolism 
Table 1 Risk factors, localisation, and clinical presentation of CVST and course and treatment during subsequent pregnancies

\begin{tabular}{|c|c|c|c|c|c|c|}
\hline Pat. & Risk factor & $\begin{array}{l}\text { Localisation } \\
\text { of CVST }\end{array}$ & Clinical presentation of CVST & Pregnancy* & $\begin{array}{l}\text { Complications } \\
\text { during pregnancy }\end{array}$ & Heparin treatment \\
\hline 1 & puerperium & SSS, LTS, LSS & headache, vomiting & 1 & none & none \\
\hline 2 & puerperium & SSS, CV & headache, seizures & 1 & $\begin{array}{l}\text { spontaneous abortion } \\
\text { (week 16) }\end{array}$ & none \\
\hline \multirow[t]{2}{*}{3} & oral contraceptives & $\begin{array}{l}\text { SSS, RS, RTS, } \\
\text { CV }\end{array}$ & headache, vomiting, stupor & 2 & $\begin{array}{l}\text { gestosis, section } \\
\text { (week 33) }\end{array}$ & none \\
\hline & & & & & none & $\begin{array}{l}\text { low dose heparin from week } \\
16\end{array}$ \\
\hline 4 & venous malformation & SSS, CV & $\begin{array}{l}\text { headache, hemiparesis, status } \\
\text { epilepticus }\end{array}$ & 1 & none & None \\
\hline 5 & $\begin{array}{l}\text { oral contraceptives, } \\
\text { corticosteroid } \\
\text { therapy }\end{array}$ & SSS, RTS, LTS & hemiparesis, aphasia & 1 & $\begin{array}{l}\text { spontaneous abortion } \\
\text { (week 16) }\end{array}$ & None \\
\hline \multirow[t]{3}{*}{6} & none & SSS, CV & headache, focal seizures, hemiparesis & 3 & none & None \\
\hline & & & & & none & None \\
\hline & & & & & none & None \\
\hline 7 & oral contraceptives & LTS, LSS & $\begin{array}{l}\text { headache, hemiparesis, focal seizures, } \\
\text { cerebellar syndrome, somnolence }\end{array}$ & 1 & none & $\begin{array}{l}\text { low dose heparin during } \\
\text { pregnancy until } 2 \text { months after } \\
\text { delivery }\end{array}$ \\
\hline 8 & oral contraceptives & LTS, LSS & $\begin{array}{l}\text { headache, abducens paresis, bilateral } \\
\text { optic disc swelling }\end{array}$ & 1 & none & None \\
\hline \multirow[t]{2}{*}{9} & oral contraceptives & SSS, CV & $\begin{array}{l}\text { headache, hemiparesis, grand mal } \\
\text { seizures, coma }\end{array}$ & 2 & $\begin{array}{l}2 \text { grand mal seizures } \\
\text { (no gestosis) }\end{array}$ & none \\
\hline & & & & & none & None \\
\hline \multirow[t]{2}{*}{10} & pregnancy (week 9) & SSS, CV & $\begin{array}{l}\text { headache, optic disc swelling, focal } \\
\text { sensory deficits }\end{array}$ & 2 & none & None \\
\hline & & & & & $\begin{array}{l}\text { gestosis, section } \\
\text { (week 31) }\end{array}$ & None \\
\hline 11 & none & LTS, LSS, ISS & headache, vomiting, somnolence & 1 & none & None \\
\hline 12 & $\begin{array}{l}\text { pregnancy (week } \\
40 \text { ) }\end{array}$ & RTS, RSS & $\begin{array}{l}\text { headache, focal seizures, retinal } \\
\text { bleeding }\end{array}$ & 2 & $\begin{array}{l}\text { none } \\
\text { none }\end{array}$ & $\begin{array}{l}\text { low dose heparin from week } \\
36 \text { until } 2 \text { weeks after delivery } \\
\text { low dose heparin from week } \\
36 \text { until } 2 \text { weeks after delivery }\end{array}$ \\
\hline 13 & oral contraceptives & SSS, CV & headache, tetraparesis, focal seizures & 1 & $\begin{array}{l}\text { induced abortion } \\
\text { (week 12) }\end{array}$ & None \\
\hline 14 & factor $\mathrm{V}$ mutation & SSS, RTS, RSS & $\begin{array}{l}\text { headache, } \mathrm{VI} \text { and } \mathrm{VII} \text { cranial nerves } \\
\text { palsy }\end{array}$ & 1 & none & $\begin{array}{l}\text { low dose heparin during } \\
\text { pregnancy until } 6 \text { weeks after } \\
\text { delivery }\end{array}$ \\
\hline
\end{tabular}

SSS, superior sagittal sinus; ISS, inferior sagittal sinus; RTS, right transverse sinus; LTS, left transverse sinus; RSS, right sigmoid sinus; LSS, left sigmoid sinus; CV, ascending cortical veins. *Number of pregnancies during the follow up period.

Hormone associated risk factors for CVST had been pregnancy and puerperium in four patients and oral contraceptives in five women. As the mean follow up period of our study included more than 10 years, screening for more recently detected coagulation disorders (for example, APC resistance, prothrombin mutation) associated with an increased risk for CVST was only available for two women of whom one had a factor $\mathrm{V}$ Leiden mutation. However, one woman had a history of pulmonary embolism and another had a family history of unexplained venous thrombotic events, which may indicate a hereditary coagulation disorder. Table 1 summarises the risk factors, localisation, and clinical presentation of the previous CVST and the course and treatment during subsequent pregnancies.

\section{DISCUSSION}

Risk assessment and counselling of women with a history of CVST regarding future pregnancies is difficult because of the lack of data concerning the associated thrombotic risk. As pregnancy and puerperium are prothrombotic risk factors for VTE, gynaecologists and general physicians are often reluctant to encourage women with previous CVST to become pregnant. The results of this study suggest that a history of CVST does not preclude a subsequent pregnancy. None of our patients had recurrence of CVST during pregnancy and puerperium and no extracerebral VTE occurred. The observed complications (for example, spontaneous abortion, gestosis) were most probably not attributable to thromboembolic complications.

Adding the 22 pregnancies from our series to other published series and case reports, ${ }^{6-9}$ there are now data avail- able from 63 pregnancies with normal delivery and without recurrence of CVST including 21 women who initially presented with pregnancy related CVST. No heparin or ASS were given during pregnancy in most of the reported cases. It is a drawback of the retrospective design of our study, that we cannot draw conclusions about the need for a prophylactic low dose anticoagulation. There is evidence of a very low risk of recurrent VTE for women with previous extracerebral venous thrombotic events, if no inherited or acquired thrombophilia is present and if the previous venous thrombosis was associated with a temporary risk factor (for example, oral contraceptives, fracture induced immobilisation, etc). ${ }^{10}$ In contrast, the risk of recurrence is increased if a thrombophilia is present or the prior thrombotic event was idiopathic. Women with either prior extracerebral or cerebral VTE who are pregnant or planning to conceive should be tested for thrombophilia, ${ }^{11}{ }^{12}$ which may help to reduce the individual risk of recurrence during subsequent pregnancies.

The decision for prophylactic anticoagulation during pregnancy in women without thrombophilia or persisting prothrombotic risk factors may also be based on the time interval between previous CVST and subsequent pregnancy. Preter $e t$ al reported a relapse rate of $11.7 \%$ in a retrospective study including 77 male and female patients and all recurrences occurred within the first 12 months. The mean follow up time was 77.8 months. We observed a rate of $6 \%$ of angiographically verified relapses for all patients during a much longer follow up period and-with one exception-all recurrences occurred within the first 24 months. Thus, for an unselected population of patients with CVST, the first two 
years may be the most vulnerable period. In our women, the mean interval from CVST to subsequent pregnancy was more than two years in all but three patients, which may have contributed to the lack of recurrence in our series. From the available data, the true risk of recurrence during pregnancy within the first two years as well as the need for prophylactic anticoagulation cannot be estimated. If CVST had occurred more than two years ago, the findings of Preter et al and our data suggest a low risk of recurrence which may not justify routine prophylactic anticoagulation. Counselling about symptoms suggestive of CVST recurrence (for example, severe headache, focal neurological signs, epileptic seizures, etc) and neurological surveillance during pregnancy may be sufficient in these cases.

The number of women treated with low dose heparin or ASS increased substantially during the postpartum period in one study, ${ }^{9}$ which may reflect the fact, that pregnancy related CVST occurs most frequently during the puerperium, ${ }^{3}$ thus increasing the readiness of physicians to apply preventive measures. Prophylactic anticoagulation is recommended in women with previous VTE during the postpartum period, ${ }^{13}$ which carries the greatest day by day risk of developing deep vein thrombosis. ${ }^{14}$ Although these data have been obtained from women with extracerebral VTE, a similar management of patients with CVST seems feasible, as cerebral and extracerebral venous thrombosis do not differ with respect to the underlying risk factors.

In conclusion, the results of our retrospective study do not justify a negative advice on pregnancy in women with a history of CVST. Further prospective studies are needed to evaluate the need of a temporary anticoagulation during pregnancy and puerperium in women with previous cerebral venous thrombosis.

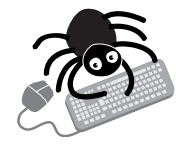

A copy of the questionnaire used in this study is available on the journal web site (www.jnnp.com/ supplemental).

\section{Authors' affiliations}

S Mehraein, H Ortwein, M Busch, M Weih, K Einhäupl, F Masuhr, Department of Neurology, Charité Medical School, Humboldt-Universität, Berlin, Germany

Competing interests: none declared.

Correspondence to: Dr F Masuhr, Department of Neurology, Charité Medical School, Humboldt-Universität, Schumannstrasse 20/21, 10117 Berlin, Germany; Florian.Masuhr@charite.de

Received 5 September 2002

Accepted in revised form 27 January 2003

\section{REFERENCES}

1 National Institutes of Health Consensus Development Conference. Prevention of venous thrombosis and pulmonary embolism. JAMA 1986;256:744-9

2 Ameri A, Bousser MG. Cerebral venous thrombosis. Neurol Clin 1992;10:87-111.

3 Cantu C, Barinagarrementeria F. Cerebral venous thrombosis associated with pregnancy and puerperium. Review of 67 cases. Stroke 1993;24:1880-4.

4 de Bruijn SFTM, Stam J, Koopman MMW, et al. for the Cerebral Venous Sinus Thrombosis Study Group. Case control study of risk of cerebral sinus thrombosis in oral contraceptive users who are carriers of hereditary prothrombotic conditions. BM 1998;316:589-92.

5 de Bruijn SFTM, Stam J, Vandenbroucke JP, for the Cerebral Venous Sinus Thrombosis Study Group. Increased risk of cerebral venous sinus thrombosis with third-generation oral contraceptives. Lancet 1998:351:1404.

6 Srinivasan K. Cerebral venous and arterial thrombosis in pregnancy and puerperium. A study of 135 patients. Angiology 1983;34:731-46.

7 Preter M, Tzourio C, Ameri A, et al. Long-term prognosis in cerebral venous thrombosis, follow-up of 77 patients. Stroke 1996;27:243-6.

8 van der Stege JG, Engelen MA, van Eyck J. Uncomplicated pregnancy and puerperium after cerebral venous thrombosis. Eur J Obstet Gynecol Reprod Biol 1997;71:99-100.

9 Lamy C, Hamon JB, Coste J, et al, for the French Study Group on Stroke and Pregnancy Neurology 2000;55:269-74.

10 Brill-Edwards P, Ginsberg JS, Gent M, et al, for The Recurrence of Clot in This Pregnancy Study Group. Safety of withholding heparin in pregnant women with a history of venous thromboembolism. N Engl J pregnant women with a his

11 Lockwood CJ. Inherited thrombophilias in pregnant patients: detection and treatment. Obstet Gynecol 2002;99:333-41.

12 Deschiens MA, Conard J, Horellou MH, et al. Coagulation studies, factor $V$ leiden, and anticardiolipin antibodies in 40 cases of cerebral venous thrombosis. Stroke 1996;27:1724-30.

13 Ginsberg JS, Greei I, Hirsh J. Use of antithrombotic agents during pregnancy. Chest 2001;119:122-31S.

14 Ray JG, Chan WS. Deep vein thrombosis during pregnancy and the puerperium: a meta-analysis of the period of risk and the leg of presentation. Obstet Gynecol Surv 1999;54:265-71. 